\title{
Biochemical and nutritional characterization of the medfly gut symbiont Enterobacter sp. AA26 for its use as probiotics in sterile insect technique applications
}

\author{
Konstantinos Azis ${ }^{1}$, Ioanna Zerva ${ }^{1}$, Paraschos Melidis ${ }^{1}$, Carlos Caceres ${ }^{2}$, Kostas Bourtzis ${ }^{2}$ and Spyridon Ntougias ${ }^{1 *}$
}

\begin{abstract}
Background: Enterobacter sp. AA26 was recently isolated from the midgut of Ceratitis capitata (Wiedemann) and it was shown to have positive effects in rearing efficiency when used as larval probiotics. In this study, biomass production was carried out in bench-scale bioreactors to elucidate the biokinetic properties of Enterobacter sp. AA26 and its nutritional value.

Results: Strain AA26 is a psychrotolerant, halotolerant, facultatively anaerobic bacterium with broad pH range for growth (pH 4 to 10.2), which possessed the typical biochemical profile of Enterobacter spp. The specific oxygen uptake rate (SOUR) was calculated as $63.2 \pm 1.26$ and $121 \pm 1.73 \mathrm{mg} \mathrm{O}_{2} \mathrm{~g}^{-1}$ VSS $\mathrm{h}^{-1}$, with the yield coefficients in acetate and glucose being equal to $0.62 \pm 0.03$ and $0.67 \pm 0.003 \mathrm{~g}$ biomass produced $/ \mathrm{g}$ substrate consumed, respectively. The maximum specific growth rate $\left(\mu_{\max }\right)$ of strain AA26 grown in fill-and-draw bioreactors at $20^{\circ} \mathrm{C}$ and $35^{\circ} \mathrm{C}$ was 0.035 and $0.069 \mathrm{~h}^{-1}$, respectively. Strain AA26 grew effectively in agro-industrial wastewaters, i.e. cheese whey wastewater (CWW), as alternative substrate for replacing yeast-based media. Biomass of strain AA26 could provide all the essential amino acids and vitamins for the artificial rearing of C. capitata. Greater intracellular a- and $\beta$-glucosidase activities were observed during growth of strain AA26 in CWW than in yeast-based substrate, although the opposite pattern was observed for the respective extracellular activities $(p<0.01)$. Low protease activity was exhibited in cells grown in yeast-based medium, while no lipase activities were detected.
\end{abstract}

Conclusions: The ability of strain AA26 to grow in agro-industrial wastes and to provide all the essential nutrients can minimize the cost of commercial media used for mass rearing and large scale sterile insect technique applications.

Keywords: Biomass valorization, Insect mass rearing, Agricultural wastes

\section{Background}

The Mediterranean fruit fly Ceratitis capitata (Wiedemann), commonly named as medfly, is one of the major insect pests worldwide. This polyphagous pest negatively affects fruit production since oviposition of adult female medflies and larvae development under the fruit skin can result in serious crop damage [1]. The sterile insect technique (SIT) has been broadly adopted to combat this

\footnotetext{
*Correspondence: sntougia@env.duth.gr

'Laboratory of Wastewater Management and Treatment Technologies,

Department of Environmental Engineering, Democritus University of Thrace,

Vas. Sofias 12, 67100 Xanthi, Greece

Full list of author information is available at the end of the article
}

destructive pest. SIT is based on the mass production and release of irradiated sterile insects. Through continuous releases of overflooding ratios of sterile insects, wild females mate with the sterile males and the target population is suppressed [2].

During the recent years, it has been shown that insects have established sophisticated symbiotic associations (e.g. parasitic or mutualistic relationships) with diverse microorganisms, including bacterial species $[3,4]$. These symbiotic bacteria play a catalytic role in the biology, physiology, ecology and evolution of insect species, 
affecting nutrition, immunity, mating behavior, reproduction and pest status of their hosts [3, 4].

The structure and properties of the gut-associated microbiota of medfly Ceratitis capitata has recently been studied [5-7]. The medfly gut was found to be dominated almost exclusively by representatives of the family Enterobacteriaceae. In particular, members of KlebsiellaEnterobacter-Citrobacter group, the ex Enterobacter linkage Pantoea genus, and Pectobacterium spp. were the predominant taxa in the gut of Ceratitis capitata [57]. The predominance of such pectinolytic and diazotrophic population appears to influence medfly's diet and fitness [5, 6, 8]. Additional studies in medfly have also indicated that irradiation-induced dysbiosis can be potentially restored by enhancing male sexual performance through Klebsiella oxytoca probiotic applications [7]. Enterobacter agglomerans, Klebsiella pneumoniae and other bacterial isolates have also been used in adult probiotic applications under laboratory conditions [9, 10]. The ability of Enterobacter-Klebsiella group members to colonize the gut biofilm of the sterile males makes advantageous their application as probiotic bacteria in mass rearing and SIT applications [11].

Recently, the gut-associated symbiont Enterobacter sp. AA26 was isolated from the Ceratitis capitata Vienna $8^{\text {D53+ }}$ genetic sexing strain (GSS) and was shown to improve the productivity of this strain [12]. To assess the potential of this symbiont in the artificial diet of medfly under mass rearing conditions and its potential costeffectiveness for large scale operational SIT programmes, large quantities of biomass are required. The present study investigates the biokinetic properties of Enterobacter sp. AA26 for mass production of biomass in fullscale bioreactors towards its potential use in mass rearing facilities and large scale applications. Indeed, mass production of Enterobacter sp. AA26 from low-cost agricultural residues, which are easily biodegradable and accessible worldwide, such as cheese whey wastewater, can substitute Torula yeast (syn. Candida utilis), minimizing thus the cost of purchasing this ingredient that is widely used for mass rearing in SIT applications.

\section{Methods}

Enterobacter sp. AA26 was isolated from the gut of the medfly Vienna $8^{\mathrm{D} 53+}$ GSS as described previously [12]. The identity of the biological material used in all tests described below was confirmed by sequencing the $16 \mathrm{~S}$ rRNA gene, which was found identical to that previously reported [12].

\section{Physiological and biochemical characteristics of Enterobacter sp. AA26}

The biochemical profile of Enterobacter sp. AA26 was examined by using the EnteroPluri kit (BD, USA), following manufacturer's instructions. Pectinase activity was examined by using pectinase screening agar medium, consisting of $1 \% \mathrm{w} / \mathrm{v}$ citrus pectin, $0.14 \% \mathrm{w} / \mathrm{v}$ $\left(\mathrm{NH}_{4}\right)_{2} \mathrm{SO}_{4}, 0.6 \% \mathrm{w} / \mathrm{v} \mathrm{K} \mathrm{HPO}_{4}, 0.2 \% \mathrm{w} / \mathrm{v} \mathrm{KH}_{2} \mathrm{PO}_{4}$ and $0.01 \% \mathrm{w} / \mathrm{v} \mathrm{MgSO}_{4} .7 \mathrm{H}_{2} \mathrm{O}$ in the presence of $1.7 \% \mathrm{w} / \mathrm{v}$ agar [13]. Pectin-containing agar plates in the presence of $0.10 \% \mathrm{w} / \mathrm{v}$ yeast extract were also prepared. Catalase and oxidase reactions were performed according to Smibert and Krieg [14].

The $\mathrm{pH}$ range for growth was investigated by using a nutritional base consisting of $10 \mathrm{~g} \mathrm{~L}^{-1}$ peptone and $5 \mathrm{~g}$ $\mathrm{L}^{-1}$ yeast extract, supplemented with the appropriate buffer solution. The following $\mathrm{pH}$ values were tested: pH 3 (adjusted by citric acid addition), pH 4 (0.06 M citric acid - 0.04 M citrate), pH $5(0.035 \mathrm{M}$ citric acid $0.065 \mathrm{M}$ citrate), pH $6 \quad\left(0.013 \mathrm{M} \quad \mathrm{Na}_{2} \mathrm{HPO}_{4}-0.087 \mathrm{M}\right.$ $\left.\mathrm{KH}_{2} \mathrm{PO}_{4}\right), \mathrm{pH} 7$ (0.061 M Na $\left.\mathrm{HPO}_{4}-0.039 \mathrm{M} \mathrm{KH}_{2} \mathrm{PO}_{4}\right)$, pH 8 (0.095 M Na $\left.\mathrm{NPO}_{4}-0.005 \mathrm{M} \mathrm{KH}_{2} \mathrm{PO}_{4}\right)$, pH 9 (0.1 M $\left.\quad \mathrm{NaHCO}_{3}-1 \mathrm{mM} \quad \mathrm{K}_{2} \mathrm{HPO}_{4}\right), \quad$ pH $10.2 \quad(0.075 \mathrm{M}$ $\mathrm{Na}_{2} \mathrm{CO}_{3}-0.025 \mathrm{M} \mathrm{NaHCO}_{3}-1 \mathrm{mM} \mathrm{K}_{2} \mathrm{HPO}_{4}$ ) and $\mathrm{pH} 11$ $\left(0.1 \mathrm{M} \mathrm{Na}_{2} \mathrm{CO}_{3}\right)$ [15]. The salt range for growth was investigated by using the above nutritional base in the presence of $0,1,3,5,8,9,10$ and $11 \%$ w/v NaCl. LB (Luria-Bertani) media were used to investigate the temperature range for growth of strain AA26 (4, 7, 11, $15,20,25,30,37,40$ and $43^{\circ} \mathrm{C}$ were tested). Anaerobic growth was examined by using the Anaerocult A anaerobic system (Merck, Germany). All the above media were solidified with $17 \mathrm{~g} \mathrm{~L}^{-1}$ agar.

\section{Determination of growth characteristics of Enterobacter sp. AA26 in batch cultures}

Growth curves were constructed by measuring the optical density at $600 \mathrm{~nm}\left(\mathrm{OD}_{600 \mathrm{~nm}}\right)$ after inoculation of $\mathrm{LB}$ liquid media with strain AA26 at $30^{\circ} \mathrm{C}$. In addition, growth of Enterobacter sp. AA26 was examined in 1:5 v/ $\mathrm{v}$ cheese whey wastewater $(10,000 \mathrm{mg} / \mathrm{L}$ final Chemical Oxygen Demand - COD concentration, with $\mathrm{pH}$ being adjusted at 7). Enterobacter sp. AA26 was also cultivated in the following growth media: I) $10 \mathrm{~g} \mathrm{~L}^{-1}$ peptone, II) $10 \mathrm{~g} \mathrm{~L}^{-1}$ peptone and $10 \mathrm{gL}^{-1} \mathrm{NaCl}$, III) $10 \mathrm{~g} \mathrm{~L}^{-1} \mathrm{glu}-$ cose and $0.2 \mathrm{gL}^{-1}$ yeast extract and IV) $10 \mathrm{~g} \mathrm{~L}^{-1}$ glucose.

\section{Biokinetic parameters of Enterobacter sp. AA26 in fill and draw bioreactors}

Samples were obtained aseptically to determine protein biomass content during bioreactor operation. In details, the obtained biomass was centrifuged at $10,000 \mathrm{~g}$ for 5 min $\left(\right.$ at $4{ }^{\circ} \mathrm{C}$ ), washed in $20 \mathrm{mM}$ Tris- $\mathrm{HCl}$ ( $\left.\mathrm{pH} 7.6\right)$ and disrupted on ice for $15 \mathrm{~min}$ (at a pulse of $0.6 \mathrm{~s}$ with $0.4-\mathrm{s}$ interval, $50 \%$ duty cycle) by using a Hielscher UP200S sonicator. The homogeneous biomass was centrifuged $\left(15,000 \mathrm{~g}\right.$ at $4{ }^{\circ} \mathrm{C}$ for $\left.15 \mathrm{~min}\right)$ and the cell-free lysate was 
collected for protein determination. Protein content was quantified by the Bradford method [16].

Laboratory-scale bioreactors of $1 \mathrm{~L}$ each (working volume of $0.6 \mathrm{~L}$ ) were fed with LB broth and inoculated aseptically with the medfly gut symbiont Enterobacter sp. AA26. The strain AA26 was grown under the fill and draw mode and the biomass growth characteristics were determined.

Oxygen uptake rate (OUR) was determined in $1 \mathrm{~L}$ working volume sterile bioreactor $(1.2 \mathrm{~L}$ in total), where dissolved oxygen was online measured using a WTW (Wissenschaftlich-Technische Werkstätten) dissolved oxygen (DO) meter. The DO meter was connected to a computer and measurements were obtained every $15 \mathrm{~s}$. An air pump was used to achieve adequate aeration (approximately $7 \mathrm{mg} / \mathrm{L}$ ) and cells agitation was performed (Fig. 1). Aeration of the culture was interrupted and the resulting decrease in the oxygen concentration was recorded as a function of time. Aeration/non-aeration cycles of $12 \mathrm{~min}$ were performed, consisting each one of 6 min aeration-on and $6 \mathrm{~min}$ aeration-off periods. OUR ( $\mathrm{mg} \mathrm{O}_{2} \mathrm{~L}^{-1} \mathrm{~h}^{-1}$ ) was estimated by determining the slope during linear decline of DO and SOUR (expressed as $\mathrm{mg}$ $\mathrm{O}_{2} \mathrm{~g}^{-1} \mathrm{VSS} \mathrm{h}^{-1}$ ) was measured by dividing OUR by the volatile suspended solids (VSS) present in the bioreactor. After passing the culture into endogenous respiration, acetate or glucose was added and both OUR and SOUR were calculated. The VSS concentration was determined as described in Standard Methods for the Examination of Water and Wastewater [17] to determine the specific oxygen uptake rate (SOUR). The yield coefficient $\left(\mathrm{Y}_{\mathrm{H}}\right)$, i.e. g biomass produced/g substrate consumed, was calculated according to the following formula $[18,19]$ :

$$
\mathrm{Y}_{\mathrm{H}}=1-\frac{O U}{S_{S}}
$$

where $\mathrm{OU}\left(\mathrm{mg} \mathrm{O}_{2} \mathrm{~L}^{-1}\right)$ is the oxygen consumed for the complete oxidation of organic substrate added (estimated by calculating the cumulative oxygen consumption area), and $\mathrm{S}_{\mathrm{S}}$, the COD concentration of the biodegradable substrate added $\left(\mathrm{mg} \mathrm{O}_{2} \mathrm{~L}^{-1}\right)$.

The specific growth rate $(\mu)$ of strain AA26 was determined by calculating the dilution rate (D) at steady operational conditions. The dilution rate can be defined by dividing the flow rate of the medium entered by the volume of the culture in the bioreactor [20]:

$$
\mu=\mathrm{D}=\frac{\text { medium flow rate }}{\text { culture volume }}
$$

The maximum specific growth rate $\left(\mu_{\max }\right)$ was determined by estimating the maximum broth flow rate, without the strain being washed-out.

\section{Determination of amino acid and vitamin compositions}

Amino acid and vitamin analyses were performed in Analytical Laboratories of Athens S. A. (Greece). Extraction of water soluble vitamins was carried out in $10 \mathrm{mM}$ ammonium acetate solution, $\mathrm{pH} 4.5$, through ultrasonic homogenization and deproteinization with $10 \% \mathrm{w} / \mathrm{v}$ trichloroacetic acid, while fat soluble vitamins were obtained after saponofication with ethanolic base $(2 \% \mathrm{w} / \mathrm{v}$ $\mathrm{NaOH}$ ) and successive hexane extractions. Both water and fat soluble vitamins were analyzed in a TSQ Quantum Access MAX Triple Quadrupole Mass Spectrometer equipped with a $50 \times 2 \mathrm{~mm}$ Phenomenex Synergi Fusion-RP LC column $(2.5 \mu \mathrm{m}$ and $100 \AA$ particles and pores size, respectively). Amino acids extraction was performed by adding $6 \mathrm{M} \mathrm{HCl}$ and $0.5 \% \mathrm{w} / \mathrm{v}$ phenol and placing the analyzed samples in a microwave oven. Detection of amino acids was carried out in a HILICESI-MS-MS system (Thermo Scientific). Protein determination in Torula yeast was performed by estimating the total Kjeldahl nitrogen (TKN) of the samples and multiplying their TKN content by a conversion factor of 6.25 (AOAC 2001.11 method).

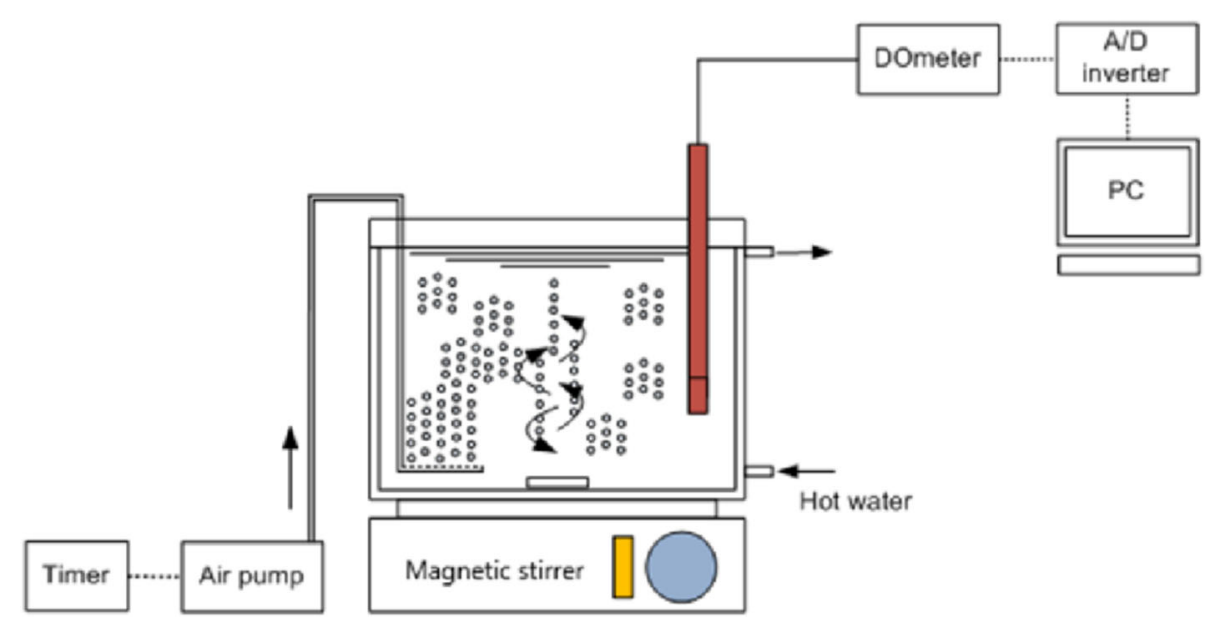

Fig. 1 Schematic layout of the unit used for oxygen uptake rate (OUR) measurements 


\section{Quantification of hydrolytic activities of Enterobacter sp.} AA26

Protease, lipase, $\alpha$ - and $\beta$-glucosidase activities were determined by growing strain AA26 in both LB and 1:5 v/v cheese whey wastewater and obtaining their cell-free lysate and supernatant (broth), respectively. Extracellular and intracellular proteolytic and lipolytic activities were determined based on the protocols reported in Gessesse et al. [21], while the protocol used for the estimation of the respective $\alpha$ - and $\beta$-glucosidase activities was based on Benitez et al. [22] protocol as modified by Ntougias [23]. The Student's t-test was used to comparatively examine the treatment means of the enzyme activities.

Proteolytic activity was measured using $0.5 \% \mathrm{w} / \mathrm{v}$ azocasein in $20 \mathrm{mM}$ Tris- $\mathrm{HCl}$. A quantity of $800 \mu \mathrm{L}$ azocasein was mixed with $200 \mu \mathrm{L}$ of lysate and incubated at $30{ }^{\circ} \mathrm{C}$ for appropriate time period (up to 1 day dependent on the sample examined). After addition of $500 \mu \mathrm{L} 15 \%$ $\mathrm{w} / \mathrm{v}$ trichloroacetic acid and $30 \mathrm{~min}$-incubation, the mixture was centrifuged at $14,000 \mathrm{~g}$ and $800 \mu \mathrm{L}$ of the clear supernatant were mixed with $200 \mu \mathrm{L} 2 \mathrm{~N} \mathrm{NaOH}$. Protease activity was determined by monitoring the absorbance at $440 \mathrm{~nm}$ against a blank.

Estimation of $\alpha$ - and $\beta$-glucosidase activities were determined by using $0.05 \mathrm{M}$ 4-nitrophenyl- $\alpha$-D-glucanopyranoside or 4-nitrophenyl-b-D-glucanopyranoside, respectively. A quantity of $0.4 \mathrm{~mL} 4$-nitrophenyl-D-glucanopyranoside ( $\alpha-$ or $\beta$-, as appropriate) was mixed with $1 \mathrm{~mL}$ lysate in the presence of $0.6 \mathrm{~mL} 0.02 \mathrm{M}$ Tris$\mathrm{HCl}$ and incubated for appropriate time period. Glucosidase activity was determined by measuring the absorbance at $410 \mathrm{~nm}$ against a blank.

Lipase activity was determined by using $20 \mathrm{mM}$ pnitrophenol palmitate as the stock solution. A working solution was made by adding $2.5 \mathrm{~mL}$ stock solution, 0.05 g gum Arabic, $0.2 \mathrm{~mL}$ Triton and $47.5 \mathrm{~mL} 20 \mathrm{mM}$ Tris$\mathrm{HCl}$ solution $(\mathrm{pH} 8)$. A quantity of $2.7 \mathrm{~mL}$ working solution was mixed with $0.3 \mathrm{~mL}$ lysate and incubated for appropriate time period. Lipase activity was determined by measuring the absorbance at $410 \mathrm{~nm}$ against a blank.

\section{Results}

\section{Physiological and biochemical traits of Enterobacter sp.} AA26

Enterobacter sp. AA26 could grow under a broad pH range, i.e. from $\mathrm{pH} 4$ to $\mathrm{pH} 10.2$. No growth of strain AA26 was observed at $\mathrm{pH} 3$ or $\mathrm{pH} 11$. Appearance of colonies was observed at day 1 after inoculation at any $\mathrm{pH}$ grown, indicating that strain AA26 is a neutrophile with a broad $\mathrm{pH}$ range for growth (both acidic and alkaline).

Isolate AA26 could grow both in the absence of salt and in the presence of $\mathrm{NaCl}$ concentration up to $10 \% \mathrm{w} /$ $\mathrm{v}$, showing optimum growth at salinities within $0-8 \% \mathrm{w} /$ $\mathrm{v} \mathrm{NaCl}$. No growth was observed at salt concentration of $11 \% \mathrm{w} / \mathrm{v} \mathrm{NaCl}$. Therefore, strain AA26 is a halotolerant bacterium, growing up to $10 \% \mathrm{w} / \mathrm{v} \mathrm{NaCl}$.

Strain AA26 could grow at a temperature range of 4 to $40{ }^{\circ} \mathrm{C}$ with a broad optimum for growth of $25-40{ }^{\circ} \mathrm{C}$, while no growth was observed at $43^{\circ} \mathrm{C}$. Based on these findings, strain AA26 can be characterized as psychrotolerant bacterium. Bacterial isolate AA26 could grow in the presence and absence of oxygen; therefore, it is a facultatively anaerobic bacterium.

In addition, growth under aerobic conditions was also detected in the presence of $10 \mathrm{~g} \mathrm{~L}^{-1}$ peptone only (without yeast extract and $\mathrm{NaCl}$ addition) as well as in medium consisting of $10 \mathrm{~g} \mathrm{~L}^{-1}$ peptone and $10 \mathrm{~g} \mathrm{~L}^{-1}$ $\mathrm{NaCl}$. No aerobic growth was observed in medium consisting of $10 \mathrm{~g} \mathrm{~L}^{-1}$ glucose only, while growth was restricted in the presence of $10 \mathrm{~g} \mathrm{~L}^{-1}$ glucose and a limited amount $\left(0.2 \mathrm{~g} \mathrm{~L}^{-1}\right)$ of yeast extract.

Based on EnteroPluri profile, strain AA26 exhibited the biochemical pattern presented in Table 1. Enterobacter sp. AA26 could ferment adonitol, glucose, lactose and sorbitol, hydrolyze urea, decarboxylate ornithine, utilize citrate and produce acetoin, but gave negative reactions for lysine decarboxylation, hydrogen sulphide production, tryptophan bioconversion to indole, phenylalanine deamination, and arabinose and dulcitol fermentation. Moreover, strain AA26 was oxidase-negative and catalase-positive, giving a strong catalase reaction. No growth was observed in the pectin-based medium in the absence and presence of yeast extract, indicating that no pectinase activity was induced by Enterobacter sp. AA26.

Table 1 Biochemical profile of Enterobacter sp. AA26 using EnteroPluri diagnostic kit

\begin{tabular}{|c|c|}
\hline \multicolumn{2}{|l|}{ Biochemical reactions } \\
\hline $\begin{array}{l}\text { Glucose fermentation/gas production in } \\
\text { anaerobiosis }\end{array}$ & positive/positive \\
\hline & $\begin{array}{l}\text { negative (slightly } \\
\text { green) }\end{array}$ \\
\hline \multirow{2}{*}{$\begin{array}{l}\text { Ornithine decarboxylation in anaerobiosis } \\
\text { Hydrogen sulphide production/indole test }\end{array}$} & positive \\
\hline & negative/negative \\
\hline Adonitol fermentation & positive \\
\hline Lactose fermentation & positive \\
\hline Arabinose fermentation & negative \\
\hline Sorbitol fermentation & positive \\
\hline Acetoin production (Voges-Proskauer) & positive \\
\hline $\begin{array}{l}\text { Dulcitol fermentation/phenylalanine } \\
\text { deamination }\end{array}$ & negative/negative \\
\hline Urea hydrolysis & positive \\
\hline Citrate utilization & positive \\
\hline
\end{tabular}


Biokinetic properties of Enterobacter sp. AA26

The growth curves of strain AA26 cultivated in LB and CWW under the batch mode are shown in Fig. 2. Based on Fig. 2, the double time $\left(t_{d}\right)$ of the strain was $20 \mathrm{~min}$ and $42 \mathrm{~min}$ in LB and CWW, which corresponded to specific growth rates $(\mu)$ of $2.08 \mathrm{~h}^{-1}$ and $0.99 \mathrm{~h}^{-1}$, respectively. The biomass produced was estimated at the late exponential phase as $2145 \pm 56 \mathrm{mg}$ dry weight/L LB $(n=3)$, whereas its protein content was determined as $56.6 \pm 6.3 \%(\mathrm{n}=3)$.

By cultivating Enterobacter sp. AA26 in a fill and draw bioreactor under sterile conditions, the maximum specific growth rate $\left(\mu_{\max }\right)$ of strain AA26 growing in LB at $20^{\circ} \mathrm{C}$ and $35^{\circ} \mathrm{C}$ was determined by calculating the maximum dilution rate $\left(D_{\text {max }}\right)$, in which the bioreactor was operated under stable conditions without the biomass being wash-out. These growth rates were estimated to be $0.035 \mathrm{~h}^{-1}$ and $0.069 \mathrm{~h}^{-1}$, respectively. The protein content of the dry biomass under the fill and draw operating conditions was calculated as $53.7 \pm 1.2 \% \quad(n=3)$. The respective content in Torula yeast was determined as $44.2 \pm 0.4 \%$.

Oxygen uptake and specific oxygen uptake rates were calculated by using acetate and glucose as the substrate consumed (Table 2 and Fig. 3). The oxygen uptake rates and the specific oxygen uptake rates were determined as equal to $79.6 \pm 1.59 \mathrm{mg} \mathrm{O}_{2} \mathrm{~L}^{-1} \mathrm{~h}^{-1}$ and $63.16 \pm 1.26 \mathrm{mg}$ $\mathrm{O}_{2} \mathrm{~g}^{-1}$ VSS h$^{-1}$ as well as $71.4 \pm 6.76 \mathrm{mg} \mathrm{O}_{2} \mathrm{~L}^{-1} \mathrm{~h}^{-1}$ and $121 \pm 1.73 \mathrm{O}_{2} \mathrm{~g}^{-1} \mathrm{VSS} \mathrm{h}^{-1}$ for acetate and glucose, respectively. Based on the formula $\mathrm{Y}_{\mathrm{H}}=1-\frac{O U}{S_{S}}$, the yield coefficients were calculated to be $0.62 \pm 0.03$ and $0.67 \pm$ $0.003 \mathrm{~g}$ biomass produced/g substrate consumed by using acetate and glucose as the substrates consumed (Table 3).

\section{Comparison of amino acid and vitamin compositions of Enterobacter sp. AA26 and Torula yeast}

Enterobacter sp. AA26 could synthesize all the essential amino acids, possessing an amino acid composition
Table 2 Oxygen uptake rate (OUR) and specific oxygen uptake rate (SOUR) of Enterobacter sp. AA26 cells. The food to microorganism ratio was set at $0.2 \mathrm{~g}$ substrate $\mathrm{g}^{-1} \mathrm{VSS}^{-1}$ immediately after interrupting the aeration

\begin{tabular}{llll}
\hline & Replicates & OUR $\left(\mathrm{mg} \mathrm{O}_{2} \mathrm{~L}^{-1} \mathrm{~h}^{-1}\right)$ & SOUR $\left(\mathrm{mg} \mathrm{O}_{2} \mathrm{~g}^{-1} \mathrm{VSS} \mathrm{h}^{-1}\right)$ \\
\hline Acetate & 1 & 78.5 & 62.3 \\
& 2 & 82.7 & 65.6 \\
3 & 77.5 & 61.5 \\
& Mean \pm SE & $79.6 \pm 1.59$ & $63.2 \pm 1.26$ \\
Glucose & 1 & 69.6 & 118 \\
& 2 & 83.9 & 142 \\
3 & 60.7 & 103 \\
& Mean \pm SE & $71.4 \pm 6.76$ & $121 \pm 1.73$ \\
\hline
\end{tabular}

consisted mainly of arginine, aspartic acid, leucine and lysine, which represented $33 \%$ of its protein content (Fig. 4). Torula yeast, which is one of the main ingredients in the artificial diet of medfly, also contained all the essential amino acids, although in this case, glutamic acid, valine and proline were the major amino acids detected, covering $31 \%$ of the yeast's protein content (Fig. 4). Statistically greater glutamic acid and proline content ( $p<0.01$ in Student t-test) was detected in Candida utilis compared to Enterobacter sp. AA26 cells, whereas the percentages of arginine, glycine, leucine and serine were greater $(p<0.05$ in Student t-test) in Enterobacter sp. AA26 cells than in Torula yeast (Fig. 4).

Niacin was the major vitamin detected in Enterobacter sp. AA26 and Candida utilis cells. However, niacin in Torula yeast was approximately 5 fold greater than the respective content in strain AA26 (Fig. 5). No substantial differences between Enterobacter sp. AA26 and Torula yeast were found for vitamin B5, B6, B7, B9 and E, while greater vitamin A, B2, K1 and D3 content was determined for Torula yeast as compared to Enterobacter sp. AA26 (Fig. 5). Vitamins B1, B7 and B9 were only detected in AA26 cells, but
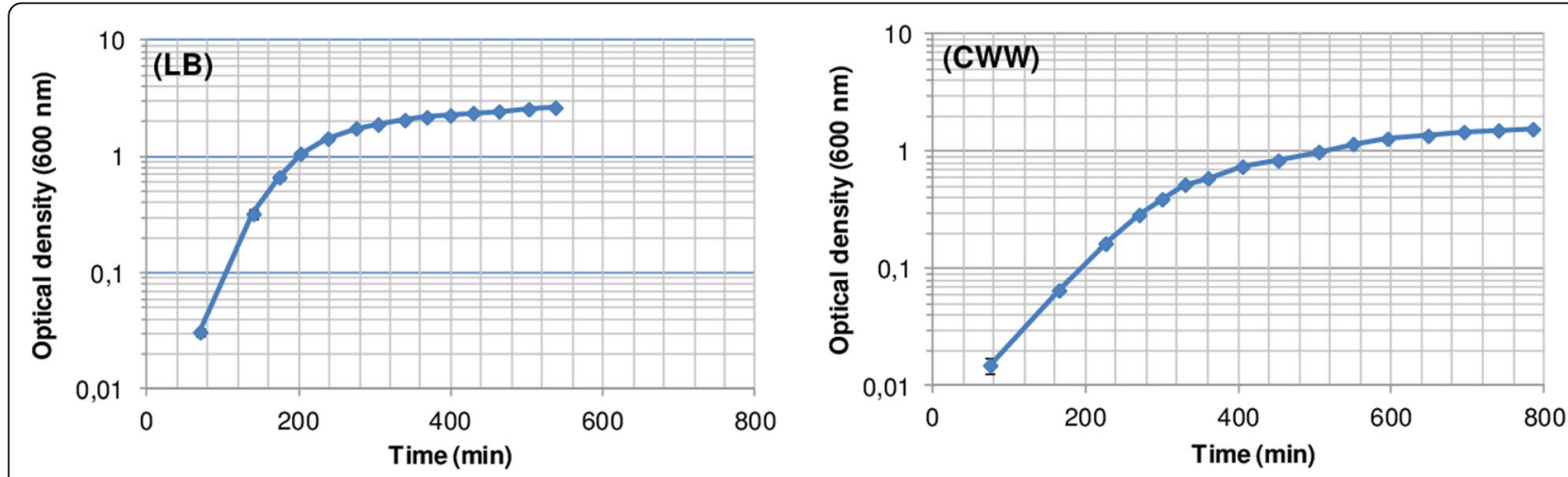

Fig. 2 Growth curves of Enterobacter sp. AA26 during cultivation in LB broth (left) and CWW (right) $(n=3)$ 

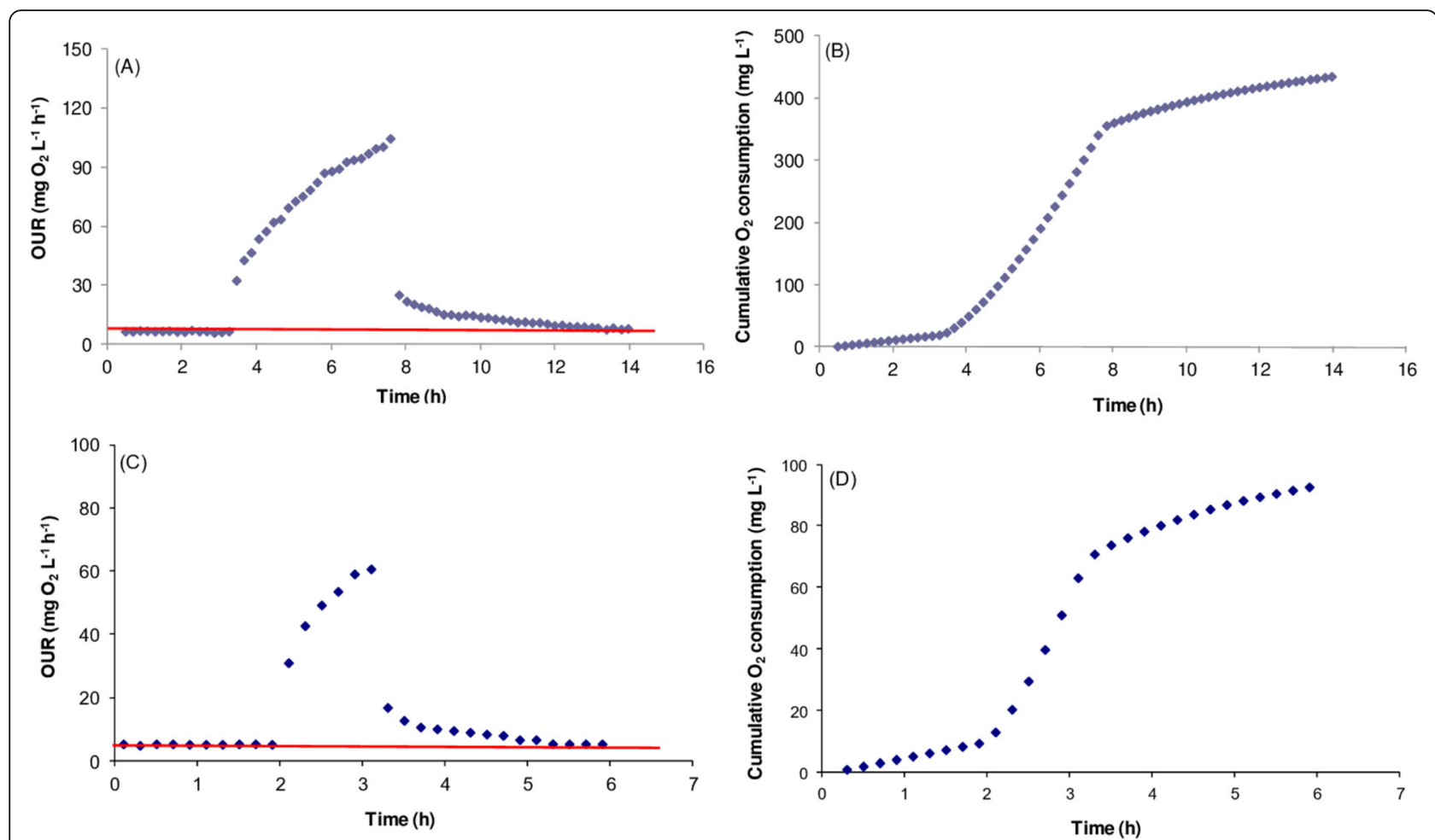

Fig. 3 Profiles of oxygen uptake rate (a and $\mathbf{c}$, for acetate and glucose, respectively) and cumulative $\mathrm{O}_{2}$ consumption (b and $\mathbf{d}$, for acetate and glucose respectively) in Enterobacter sp. AA26

only thiamine was found in reasonable amount (Fig. 5).

\section{Hydrolytic activities of Enterobacter sp. AA26 grown in} yeast-based media and cheese whey wastewaters

The glucosidase, protease and lipase activities of the lysates of strain AA26 cultivated in LB and CWW are presented in Fig. 6. Greater $\alpha$ - and $\beta$-glucosidase activities were observed during growth of strain AA26 in CWW, while the respective activities were almost half in the case of growth in LB broth $(p<0.01$ in Student's t-test). Moreover, low protease activity was exhibited by the

Table 3 Determination of yield coefficient $\left(Y_{H}\right)$ of Enterobacter sp. AA26

\begin{tabular}{lll}
\hline & Replicates & $\mathrm{Y}_{\mathrm{H}}$ (g biomass produced/g substrate consumed) \\
\hline Acetate & 1 & 0.59 \\
& 2 & 0.68 \\
& 3 & 0.60 \\
& Mean \pm SE & $0.62 \pm 0.03$ \\
Glucose & 1 & 0.67 \\
& 2 & 0.66 \\
& 3 & 0.67 \\
& Mean \pm SE & $0.67 \pm 0.003$ \\
\hline
\end{tabular}

"LB" lysate, while no lipase activities were detected in the lysates derived from the growth of strain AA26 in LB and CWW. No statistical significant differences were found between $\alpha$ - and $\beta$ - glucosidase activities determined in "CWW" lysate.

In comparison to CWW where low extracellular glucosidase activities were detected, significant higher extracellular enzyme activities were observed when Enterobacter sp. AA26 grew in LB medium $(p<0.01$ in Student's t-test) (Fig. 6). However, $\alpha$-glucosidase activity was greater than the $\beta$-glucosidase activity determined during growth of strain AA26 in both LB broth and CWW $(p<0.01$ in Student's t-test) (Fig. 6).

\section{Discussion}

The limited number of technologies to adequately produce novel biocontrol and probiotic agents is the main obstacle to their biotechnological application. A range of parameters, such as cultivation method and conditions, storage, formulation and reconstitution process, should be extensively examined for real-scale applications [24]. A few studies have been performed on the cultivation of Enterobacter spp., which is mainly restricted to hydrogen production from the fermentation of wastes [25, 26] and exopolysaccharide production [27]. No biocontrol or probiotic agent belonging to the genus Enterobacter has been cultivated in bioreactors for biotechnological 


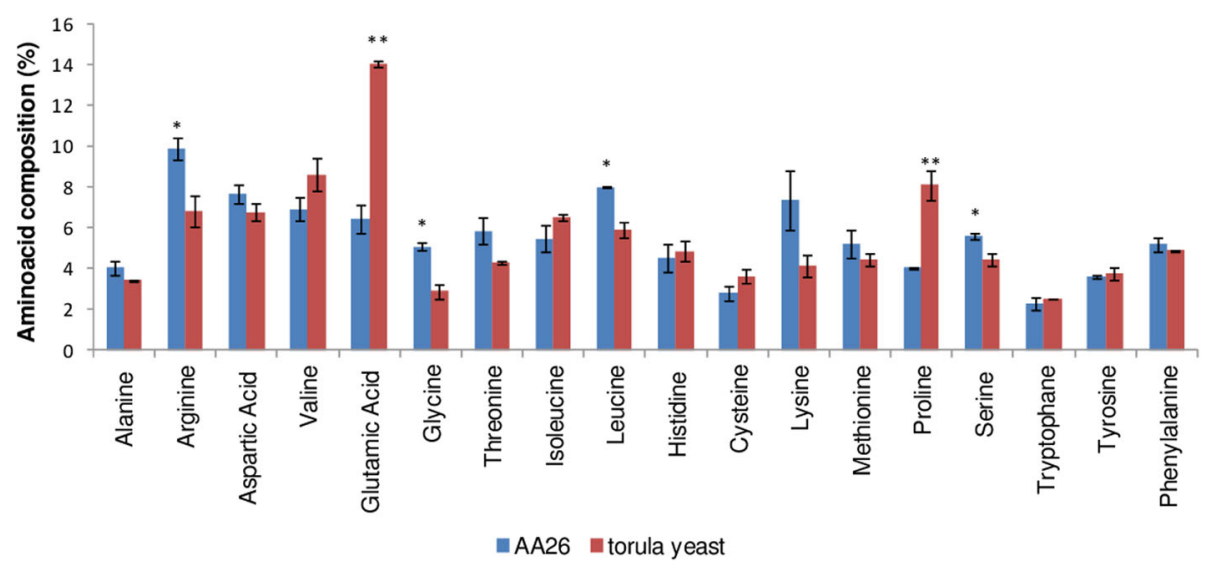

Fig. 4 Amino acid composition of Enterobacter sp. AA26 and Torula yeast

purposes and the investigation of biomass characteristics is a challenging task.

Based on the examination of physiological characteristics, Enterobacter sp. AA26 is a psychrotolerant, halotolerant, facultatively anaerobe with broad growth $\mathrm{pH}$ range. The ability of this isolate to grow under a wide $\mathrm{pH}$ range and high salt concentrations indicates that strain AA26 can be effectively adapted at various habitats. Thus, substrates of high salinity and/or low or high $\mathrm{pH}$ like several agro-industrial wastewater can be considered as potential low-cost alternative growth media. The inability of the strain to grow over $40^{\circ} \mathrm{C}$ may negatively affect its use as probiotic agent at high ambient temperatures, which is, however, not the case for its insect host Ceratitis capitata.
On the other hand, Enterobacter sp. AA26 could utilize peptone as the sole carbon source for growth, a fact that reduces the cost of cultivation since no yeast extract addition is required. This is in accordance with the findings of Potrikus and Breznak [28] who reported that peptone was an ideal nitrogen source for the cultivation of Enterobacter agglomerans strains $\mathrm{C}-1$ and $\mathrm{C}-2$. Moreover, pectinolytic population has been reported to influence medfly's diet and fitness [8]. However, no pectinase activity was exhibited by Enterobacter sp. AA26, indicating that this medfly gut-associated symbiont did not possess a mode of action that is linked to pectin degradation.

As a member of the genus Enterobacter, strain AA26 fermented lactose and glucose, producing gas, and it was

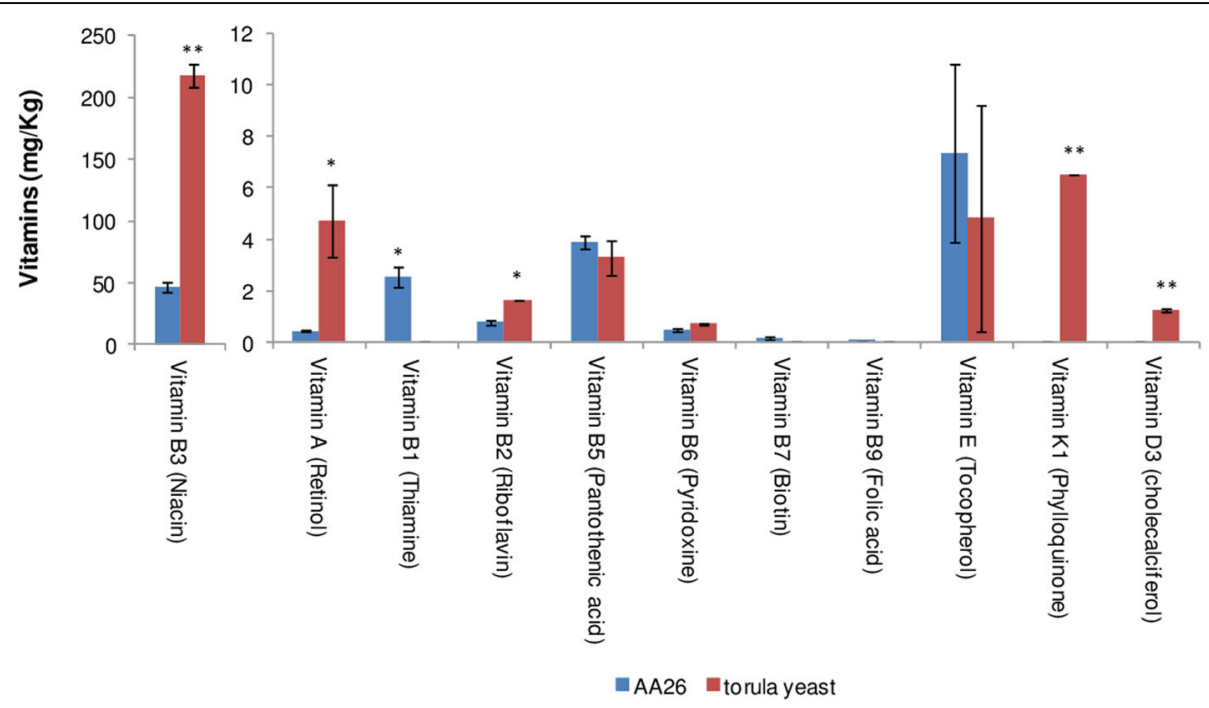

Fig. 5 Vitamin composition of Enterobacter sp. AA26 and Torula yeast. Vitamins B12, C, D3, K1 and K3 in strain AA26 and vitamins B1, B7, B9, B12, C and K3 in Torula yeast were below the detection limit. The detection limits of vitamins B1, B7, B9, B12, C, D3, K1 and K3 were 0.013, 0.01, 0.023, $0.1,7,0.01,0.02$ and $0.01 \mathrm{mg} / \mathrm{Kg}$, respectively. Vitamin contents were compared by Student's t-test, apart from the vitamins B7 and B9, which were marginally above the detection limit in the case of AA26 cells 


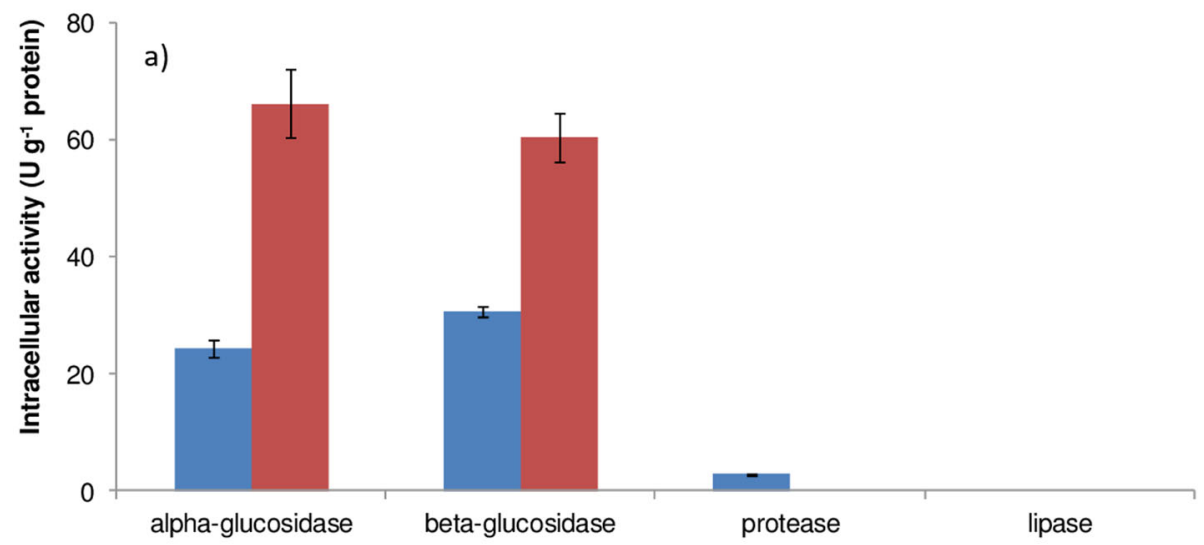

- LB $=\mathrm{CWW}$

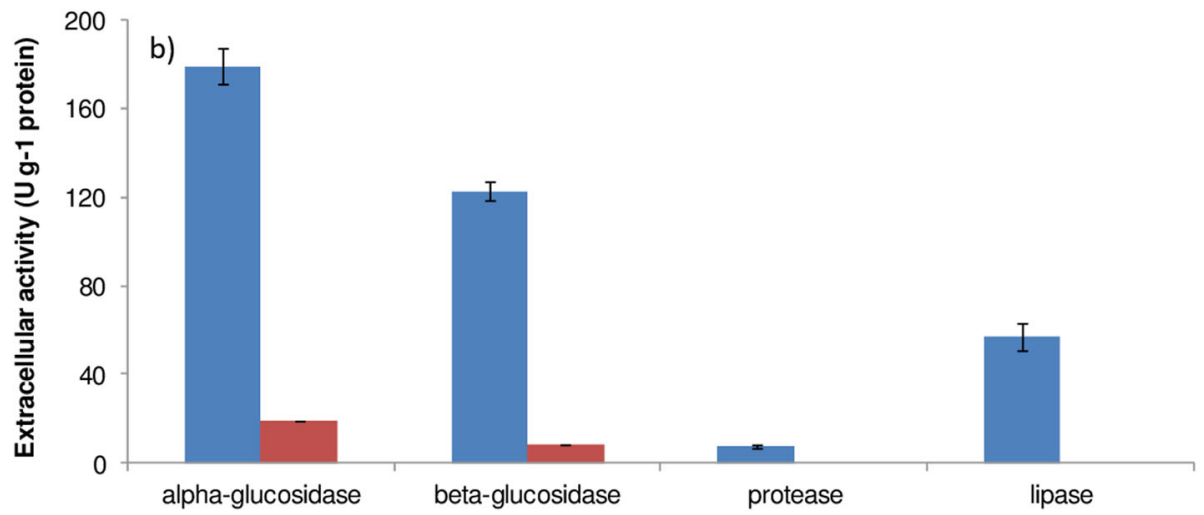

Fig. 6 Intracellular (a) and extracellular (b) hydrolytic activities of Enterobacter sp. AA26 cultivated in commercial available yeast-based medium and cheese whey wastewater

oxidase-negative, indole-negative and Voges-Proskauerpositive. Moreover, it decarboxylated ornithine, lacked phenylalanine deaminase activity and did not produce $\mathrm{H}_{2} \mathrm{~S}$. As a typical facultative anaerobe, Enterobacter sp. AA26 was oxidase-negative, which exerted a strong catalase reaction to tolerate the oxidative stress induced by oxygen species.

Enterobacter sp. AA26 exhibited among the highest specific growth rates ever reported for Enterobacter cloacae strains cultivated in yeast-based [29] and sugarbased [30] media under the batch mode. On the other hand, greater dilution rates for E. cloacae WD7 were detected [31]. Moreover, the yield coefficient $(\mathrm{Yx} / \mathrm{s})$ of strain WD7 was estimated as $0.03 \mathrm{~g}$ cells/g sucrose, which is much less than that calculated for strain AA26.

Enterobacter sp. AA26 and Torula yeast differed greatly in the proportion of glutamic acid and proline, although smaller differences were identified in the percentages of arginine, glycine, leucine and serine (Fig. 4). It is well known that amino acid effects on insect fitness are dose- and type-dependent [32, 33]. In comparison to known amino acid-rich medfly larval and adult diets
[34], glutamic acid and proline represented 6.5 and $4.1 \%$ of the protein content in strain AA26, while the respective percentages in defined diets were 21.5 and $7.8 \%$, respectively [34]. All the other amino acids were in greater proportion in strain AA26 as compared to the defined diets. In general, both glutamic acid and proline are considered as non-essential amino acids for insect species [33]. C. capitata larvae reared without glutamic acid and/or proline could be developed in a similar manner with that fed with a complete medfly meridic diet, although adverse effects have been reported from the absence of such amino acids in C. capitata adult diet [34]. Moreover, lack of threonine and tryptophan in medfly diet has been reported to induce severe effects on insect development, with no larvae survival within a period of 18 days [34]. However, these essential to medfly amino acids were in adequate proportion in strain AA26 and similar to those found in Torula yeast. The amino acids glycine and serine, which play key role in medfly fitness, were also in greater proportions in strain AA26 than in Torula yeast [35]. 
Niacin was the major vitamin detected in both Enterobacter sp. AA26 and Torula yeast [36]. Despite the fact that niacin in Torula yeast analyzed was approximately 5 -fold greater than the respective content in strain AA26, other yeasts and yeast-based products used for mass rearing contained similar to strain AA26 niacin content [36]. This indicates that the use of Enterobacter sp. AA26 biomass in medfly diet can provide all the required vitamins.

Distinct enzyme profiles were obtained for strain AA26 when it grew in LB broth and CWW, a fact that may influence the effects of strain AA26 on medfly diet and attractiveness. In particular, greater intracellular rather than exocellular $\alpha$ - and $\beta$-glucosidase activities were determined during growth of strain AA26 in CWN, while the opposite trend was observed in LB broth. The high exopolysaccharides content secreted by Enterobacter cloacae strains [31] may be responsible for the high extracellular glucosidase activities detected in LB medium during growth of strain AA26. In addition, the greater intracellular as compared to exocellular glucosidase activities during growth in CWW indicate that CWW carbohydrates (mainly glucose and lactose) were easily accessible in the cytosol. Lactose carriers have been found in phylogenetic relatives of enterobacteria, i.e. Klebsiella and Citrobacter strains [37, 38], and in the genome of Enterobacter cloacae UW5 (GenBank Accession number NZ_CP011798). On the other hand, strain AA26 was capable of growing effectively in agricultural wastewaters $\left(t_{d}\right.$ of $42 \mathrm{~min}$ in CWW) and therefore, use of such organic substrate can replace the costly substrates used for the preparation of LB, i.e. commercial yeast and peptone. Regarding CWW, Enterobacter spp. have been used in producing biohydrogen during dark fermentation of this agro-industrial effluent [39], whereas the bioconversion of cheese whey by Enterobacter sp. A47 to the bioactive compounds glucuronic acid and fucose, which can be used in potential highvalue nutraceutical and pharmaceutical applications, was recently reported [40]. Moreover, as shown in Fig. 6, Enterobacter sp. AA26 isolated from the midgut of Ceratitis capitata exerted high $\beta$-glucosidase (cellobiase) activities. The induction of cellobiases has been reported to be favored in the midgut of insect species [41]. Interestingly, Anand et al. [42] isolated an Enterobacter sp. from the gut of Bombyx mori that exhibited high $\beta$-glucosidase activity, reporting that most $B$. mori disaccharidases have been found in the midgut tissues. Possible role of such microbe on cellulose degradation of the fruit biomass digested by Ceratitis capitata cannot be excluded.

\section{Conclusions}

Enterobacter sp. AA26 was capable of being cultivated under broad environmental conditions and could grow effectively in both commercial yeast-based media and agricultural wastewaters by implementing the batch and the fill-draw mode of operation. The replacement of peptone and yeast, which commonly used in commercial media, with alternative organic substrates like agroindustrial wastes may potentially minimize the cultivation cost in full-scale insect mass rearing facilities. Moreover, Enterobacter sp. AA26 as a probiotic strain is capable of providing the entire spectrum of both essential and non-essential amino acids and vitamins in adequate amount for medfly mass rearing and sterile insect technique applications.

\section{Abbreviations}

CWW: Cheese whey wastewater; DO: Dissolved oxygen; GSS: Genetic sexing strain; OUR: Oxygen uptake rate; SIT: Sterile insect technique; SOUR: Specific oxygen uptake rate; $t_{d}$ : Double time; VSS: Volatile suspended solids; $Y_{H}$ : Yield coefficient; $\mu$ : Specific growth rate; $\mu_{\max }$ : Maximum specific growth rate

\section{Acknowledgements}

This research was funded by the International Atomic Energy Agency (IAEA) in the frame of the research project "Cultivation of the Medfly Gut Symbiont Enterobacter sp. AA26 in a Suspension Bioreactor for Mass Rearing and Sterile Insect Technique Application" (IAEA Research Contract No. 18780/R0 granted to Spyridon Ntougias) that is part of the IAEA's Coordinated Research Project "D41024", entitled "Use of Symbiotic Bacteria to Reduce Mass-rearing Costs and Increase Mating Success in Selected Fruit Pests in Support of SIT Application".

\section{About this supplement}

This article has been published as part of BMC Biotechnology Volume 19 Supplement 2, 2019: Proceedings of an FAO/IAEA Coordinated Research Project on Use of Symbiotic Bacteria to Reduce Mass-rearing Costs and Increase Mating Success in Selected Fruit Pests in Support of SIT Application: biotechnology. The full contents of the supplement are available online at https:// bmcbiotechnol.biomedcentral.com/articles/supplements/volume-19supplement-2.

\section{Authors' contributions}

$\mathrm{KA}$ and PM performed the bioengineering work; IZ and SN performed the physiological and biochemical (enzyme analysis) work and determined the specific growth rates in batch experiments; and $\mathrm{CC}$ and $\mathrm{KB}$ arranged the amino acid and vitamin analysis. CC, KB and SN conceived the idea; SN supervised the work and drafted the paper. All authors were involved in editing the paper, reading it and approving of the final manuscript.

\section{Funding}

This research was funded by the International Atomic Energy Agency (IAEA) in the frame of the research project "Cultivation of the Medfly Gut Symbiont Enterobacter sp. AA26 in a Suspension Bioreactor for Mass Rearing and Sterile Insect Technique Application" (IAEA Research Contract No. 18780/R0 granted to Spyridon Ntougias) that is part of the IAEA's Coordinated Research Project "D41024", entitled "Use of Symbiotic Bacteria to Reduce Mass-rearing Costs and Increase Mating Success in Selected Fruit Pests in Support of SIT Application"

\section{Availability of data and materials}

All data is included in the manuscript

Ethics approval and consent to participate

Not applicable.

Consent for publication

Not applicable.

Competing interests

The authors declare that they have no competing interests. 


\section{Author details}

Laboratory of Wastewater Management and Treatment Technologies, Department of Environmental Engineering, Democritus University of Thrace Vas. Sofias 12, 67100 Xanthi, Greece. ${ }^{2}$ Insect Pest Control Laboratory, Joint FAO/IAEA Programme of Nuclear Techniques in Food and Agriculture, A-1400, Vienna, Austria.

\section{Published: 18 December 2019}

\section{References}

1. Robinson AS, Hooper G. Fruit flies: their biology, natural enemies and control. Amsterdam: Elsevier; 1989.

2. Dyck VA, Hendrichs J, Robinson AS. Sterile insect technique: principles and practice in area-wide integrated pest management. Dordrecht: Springer; 2005.

3. Bourtzis K, Miller TA. Insect Symbiosis, vol. 3. Boca Raton, Florida: CRC Press; 2008.

4. Engel P, Moran NA. The gut microbiota of insects - diversity in structure and function. FEMS Microbiol Rev. 2013;37(5):699-735.

5. Behar A, Yuval B, Jurkevitch E. Enterobacteria-mediated nitrogen fixation in natural populations of the fruit fly Ceratitis capitata. Mol Ecol. 2005;14(9): 2637-43.

6. Behar A, Yuval B, Jurkevitch E. Community structure of the Mediterranean fruit fly microbiota: seasonal and spatial sources of variation. Isr J Ecol Evol. 2008;54(2):181-91.

7. Ami EB, Yuval B, Jurkevitch E. Manipulation of the microbiota of mass-reared Mediterranean fruit flies Ceratitis capitata (Diptera: Tephritidae) improves sterile male sexual performance. ISME J. 2010;4(1):28-37.

8. Ben-Yosef M, Jurkevitch E, Yuval B. Effect of bacteria on nutritional status and reproductive success of the Mediterranean fruit fly Ceratitis capitata. Physiol Entomol. 2008;33(2):145-54

9. Niyazi N, Lauzon CR, Shelly TE. Effect of probiotic adult diets on fitness components of sterile male Mediterranean fruit flies (Diptera: Tephritidae) under laboratory and field cage conditions. J Econ Entomol. 2004;97(5): 1570-80.

10. Hamden H, Guerfali MM, Fadhl S, Saidi M, Chevrier C. Fitness improvement of mass-reared sterile males of Ceratitis capitata (Vienna 8 strain) (Diptera: Tephritidae) after gut enrichment with probiotics. J Econ Entomol. 2013; 106(2):641-7.

11. Lauzon CR, McCombs SD, Potter SE, Peabody NC. Establishment and vertical passage of Enterobacter (Pantoea) agglomerans and Klebsiella pneumoniae through all life stages of the Mediterranean fruit fly (Diptera: Tephritidae). Ann Entomol Soc Am. 2009;102(1):85-95.

12. Augustinos AA, Kyritsis GA, Papadopoulos NT, Abd-Alla AMM, Cáceres C, Bourtzis K. Exploitation of the medfly gut microbiota for the enhancement of sterile insect technique: use of Enterobacter sp. in larval diet-based probiotic applications. PLoS One. 2015;10(9):e0136459.

13. Soares MMCN, Da Silva R, Gomes E. Screening of bacterial strains for pectinolytic activity: characterization of the polygalacturonase produced by Bacillus sp. Rev Microbiol. 1999;30(4):299-303.

14. Smibert RM, Krieg NR. Phenotypic characterization. In: Gerhardt P, Murray RGE, Wood WA, Krieg NR, editors. Methods for general and molecula bacteriology. Washington DC: American Society for Microbiology; 1994. p. 607-54

15. Ntougias S, Zervakis Gl, Ehaliotis C, Kavroulakis N, Papadopoulou KK. Ecophysiology and molecular phylogeny of bacteria isolated from alkaline two-phase olive mill wastes. Res Microbiol. 2006;157(4):376-85.

16. Bradford MM. Rapid and sensitive method for the quantitation of microgram quantities of protein utilizing the principle of protein-dye binding. Anal Biochem. 1976;72:248-54.

17. Clesceri LS, Greenberg AE, Eaton AD. Standard Methods for the Examination of Water and Wastewater. 20th ed. Washington, DC: American Public Health Association (APHA); 1998

18. Strotmann UJ, Geldern A, Kuhn A, Gendig C, Klein S. Evaluation of a respirometric test method to determine the heterotrophic yield coefficient of activated sludge bacteria. Chemosphere. 1999;38(15):3555-70.

19. Hagman M, La Cour Jansen J. Oxygen uptake rate measurements for application at wastewater treatment plants. VATTEN (Lund). 2007;63:131-8.

20. Waits MJ, Morgan NL, Rockey JS, Higton G. Industrial microbiology: an introduction. Oxford: Wiley-Blackwell; 2001.
21. Gessesse A, Dueholm T, Petersen SB, Nielsen PH. Lipase and protease extraction from activated sludge. Water Res. 2003;37(15):3652-7.

22. Benitez E, Sainz H, Nogales R. Hydrolytic enzyme activities of extracted humic substances during the vermicomposting of a lignocellulosic olive waste. Bioresour Technol. 2005;96(7):785-90.

23. Ntougias S. Phylogenetic identification and enzyme activities of indigenous bacteria from a landfill stabilization pond. Environ Process. 2016;3:341-52.

24. Slininger PJ, Schisler DA. High-throughput assay for optimising microbial biological control agent production and delivery. Biocontrol Sci Tech. 2013; 23(8):920-43.

25. Kim B-C, Deshpande TR, Chun J, Yi SC, Kim H, Um Y, et al. Production of hydrogen and volatile fatty acid by Enterobacter sp. T4384 using organic waste materials. J Microbiol Biotechnol. 2013;23(2):189-94.

26. Subudhi S, Nayak T, Ram Kumar N, Vijayananth P, Lal B. Impact of regulated $\mathrm{pH}$ on proto scale hydrogen production from xylose by an alkaline tolerant novel bacterial strain, Enterobacter cloacae DT-1. Int J Hydrogen Energ. 2013, 38(6):2728-37.

27. Bandaiphet $C$, Prasertsan P. Effect of aeration and agitation rates and scaleup on oxygen transfer coefficient, KLa in exopolysaccharide production from Enterobacter cloacae WD7. Carbohydr Polym. 2006;66(2):216-28.

28. Potrikus CJ, Breznak JA. Nitrogen fixing Enterobacter agglomerans isolated from guts of wood eating termites. Appl Environ Microbiol. 1977:33(2):3929.

29. Wimpenny JWT, Lewis MWA. The growth and respiration of bacterial colonies. J Gen Microbiol. 1977;103(1):9-18.

30. Prasertsan P, Dermlim W, Doelle H, Kennedy JF. Screening, characterization and flocculating property of carbohydrate polymer from newly isolated Enterobacter cloacae WD7. Carbohydr Polym. 2006;66(3):289-97.

31. Prasertsan P, Wichienchot S, Doelle H, Kennedy JF. Optimization for biopolymer production by Enterobacter cloacae WD7. Carbohydr Polym. 2008;71(3):468-75.

32. Zografou EN, Tsiropoulos GJ, Margaritis LH. Survival, fecundity and fertility of Bactrocera oleae, as affected by amino acid analogues. Entomol Exp Appl. 1998;87(2):125-32

33. Chang CL, Albrecht C, El-Shall SSA, Kurashima R. Adult reproductive capacity of Ceratitis capitata (Diptera: Tephritidae) on a chemically defined diet. Ann Entomol Soc Am. 2001:94(5):702-6.

34. Chang CL. Effect of amino acids on larvae and adults of Ceratitis capitata (Diptera: Tephritidae). Ann Entomol Soc Am. 2004;97(3):529-35.

35. Nestel D, Nemny-Lavy E, Chang CL. Lipid and protein loads in pupating larvae and emerging adults as affected by the composition of Mediterranean fruit fly (Ceratitis capitata) meridic larval diets. Arch Insect Biochem Physiol. 2004:56(3):97-109.

36. Chang CL. Evaluation of yeasts and yeast products in larval and adult diets for the oriental fruit fly, Bactrocera dorsalis, and adult diets for the medfly, Ceratitis capitata, and the melon fly, Bactrocera curcurbitae. J Insect Sci. 2009; 9(23):1-9.

37. Lee J-I, Okazaki N, Tsuchiya T, Wilson TH. Cloning and sequencing of the gene for the lactose carrier of Citrobacter freundii. Biochem Biophys Res Commun. 1994:203(3):1882-8.

38. McMorrow I, Chin DT, Fiebig K, Pierce JL, Wilson DM, Reeve ECR, et al. The lactose carrier of Klebsiella pneumoniae M5a1; the physiology of transport and the nucleotide sequence of the lacY gene. BBA Biomembranes. 1988; 945(2):315-23.

39. Rai PK, Singh SP, Asthana RK. Biohydrogen production from cheese whey wastewater in a two-step anaerobic process. Appl Biochem Biotechnol. 2012:167(6):1540-9.

40. Antunes S, Freitas F, Alves VD, Grandfils C, Reis MAM. Conversion of cheese whey into a fucose- and glucuronic acid-rich extracellular polysaccharide by Enterobacter A47. J Biotechnol. 2015;210:1-7.

41. Byeon GM, Lee KS, Gui ZZ, Kim I, Kang PD, Lee SM, et al. A digestive betaglucosidase from the silkworm, Bombyx mori: cDNA cloning, expression and enzymatic characterization. Comp Biochem Physiol. 2005;141:418-27.

42. Anand AAP, Vennison SJ, Sankar SG, Prabhu DIG, Vasan PT, Raghuraman T, et al. Isolation and characterization of bacteria from the gut of Bombyx mori that degrade cellulose, xylan, pectin and starch and their impact on digestion. J Insect Sci. 2010;10:107.

\section{Publisher's Note}

Springer Nature remains neutral with regard to jurisdictional claims in published maps and institutional affiliations. 